\title{
BUBBLE EVOLUTION IN THE TITANIUM ALLOY MELT UNDER VERTICAL CENTRIFUGAL FIELD
}

\author{
Qin $X_{u^{1 *}}$ - Xing Wang ${ }^{1}$ - Shiping $W^{2}$
}

${ }^{1}$ School of Mechanic and Electrical Engineering, Henan University of Technology, Zhengzhou 450001, China

${ }^{2}$ School of Materials Science and Engineering, Harbin Institute of Technology, Harbin 150001, China

\begin{tabular}{l}
\hline ARTICLE INFO \\
\hline Article history: \\
Received: 8.1 .2018$. \\
Received in revised form: 7. 5. 2018. \\
Accepted: 10.5 .2018$. \\
\hline Keywords: \\
Titanium alloy \\
Vertical centrifugal casting \\
Bubble evolution \\
Hydraulic experiment \\
\hline DOI: http://doi.org/10.30765/er.40.2.03
\end{tabular}

\section{Introduction}

The titanium alloys are considered for high temperature applications for their properties, such as low density, high specific strength and stiffness, as well as good corrosion resistance at higher temperature [1-2]. It is the most effective measure to save energy for the aircraft by adopting the titanium alloys to replace the steel structures and the aluminum structures. The specific strength of titanium alloys is infinitely higher than that of the steel whose strength and density are high, and is

\begin{abstract}
:
The bubble evolution in the liquid titanium melt under vertical centrifugal field has been studied by the hydraulic experiment simulation. The bubble migration process in the simple and complex cavities, the bubble morphology, bubble dimensional size diversification under different mould rotational speed has been investigated. The results show that the mould wall has a blocking effect on the bubble migration. The bubble migration in the simple cavity deviates from the line between the bubble initial position and the rotation shaft of the casting mould. Also, the bubbles in the complex cavity gather, re-nucleate and form new big ones for the blocking effect of the complex geometry shape on the radial movement of the bubble. The shape of bubbles in both the simple and complex cavity during the migration process is not a perfect sphere, but an elliptical shape. The critical size of bubble released from the bubble generation chamber decreases with the increment of the mould rotational speed. The diameter of the gas bubbles in the simple cavity during the migration process become bigger and bigger for the pressure difference at different positions of the cavity in the vertical centrifugal field.
\end{abstract}

also higher than that of the aluminum whose density is low with high strength [3]. In the F-22 Raptor fighter jet, about 39\% of the aircraft's structural weight is made of titanium alloys, and nearly $50 \%$ of its two wings are titanium alloys. Furthermore, about $7 \%$ of its total weight is made of titanium alloy castings by replacing the steel and the aluminum castings with the titanium alloy castings. It can finally obtain the weight-reduction of $600 \mathrm{~kg}$ which accounts for $40 \%$ of the total weightreduction of the flight [4-5]. It is thus obvious that it is a particularly effective way to reduce the weight

\footnotetext{
* Corresponding author. Tel.: +86 37167756213

E-mail address: xuqin@haut.edu.cn
} 
of the flight by extensive use of titanium alloys, and therefore improve the performance of the military aircraft.

However, the melting temperature of titanium alloys is high, and the titanium alloy melts has quite high viscosity and very poor fluidity [6]. Therefore, it is rather difficult to improve the filling ability of the titanium alloy melts by increasing the pouring temperature. However, the filling ability of titanium alloy melts can be improved by the centrifugal force developed by the high-speed rotation during vertical centrifugal casting process [7-8]. For the high centrifugal force can reduce the filling time and the temperature decline degree of the melt, and hence improve the melt fluidity. Thus, most of the titanium alloy castings with big size and high performance are mainly produced by vertical centrifugal casting process [9-11]. In another aspect, the chemical activity of the titanium alloys are very high at high temperature, and the solubility of gases in molten titanium alloys are also high [12-13]. The gas dissolved in the titanium alloy melts may form gas bubble when the temperature of the melts drops. Theoretical computation of the shrinkage criterion for the titanium alloy is 1.86 , which shows that the titanium alloys are prone to generate gas holes in the titanium alloy castings [14].

Researches have been done to study the bubble nucleation and migration in the titanium alloy melts during the vertical centrifugal casting process [1516]. However, little work has been done on the dimensional changes of the bubble during its migration in the titanium alloy melts. Therefore, the present paper will investigate the bubble migration and the dimensional changes in the titanium alloy melts during vertical centrifugal casting process by the hydraulic experiment. In addition, the effects of the mould rotational speed, the shape of the cavity, etc. have also been studied.

\section{Experimental procedure}

The schematic of the casting mould for hydraulic experiments is shown in Fig. 1. The casting mould is made from the three polymethyl methacrylate (PMMA) slices with thickness of $2 \mathrm{~mm}$ (shown in Fig. 2). The top slice and the bottom slice are joined as one body by the trichloromethane. This body will be fixed with the top slice by the small fixed holes. The casting mould consists of two different cavities, a simple cavity and a complex cavity. The two cavities are on the middle slice. In order to observe the bubble evolution in the cavities, the bubble generation chambers are preset on the bottom slice of the casting mould at the position 1 and position 2 (shown in Fig. 1a)). The schematic of the bubble generation chamber is shown in Fig. 1b). The simulated liquid used in the experiment is water with certain amount of tackifier to make the viscosity of the simulated medium identical to that of the titanium alloy [17-18].

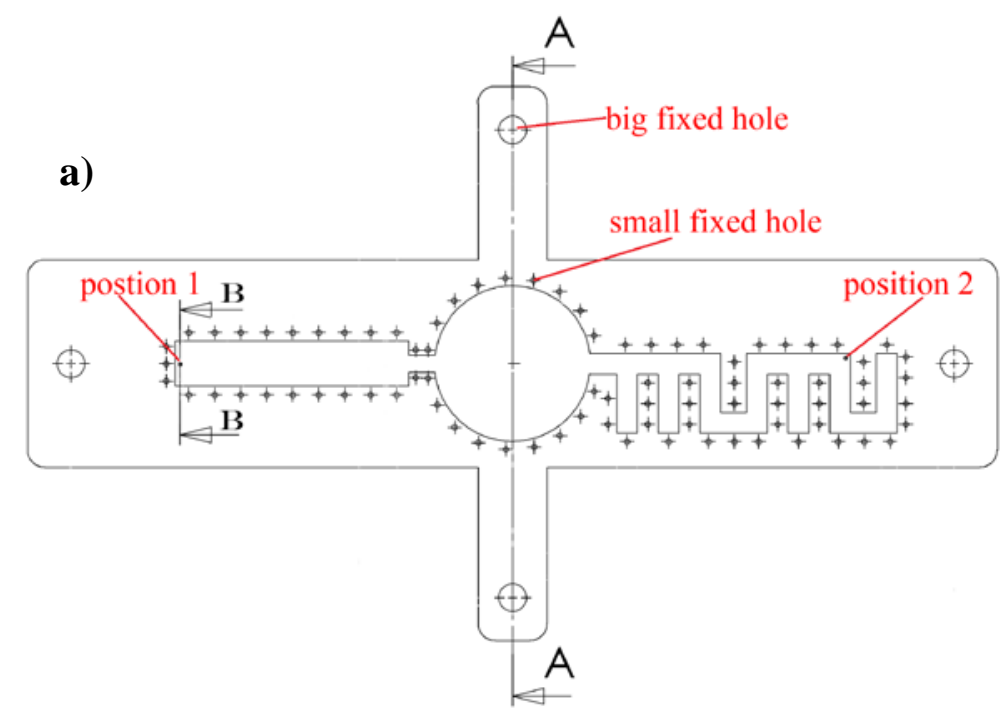

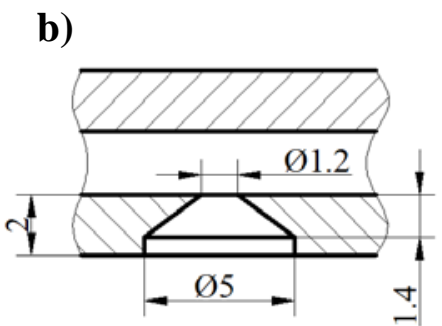

B-B sectional profile

Figure 1. The schematic of the polymethyl methacrylate casting mould a) the casting mould; b) the bubble generation chamber 


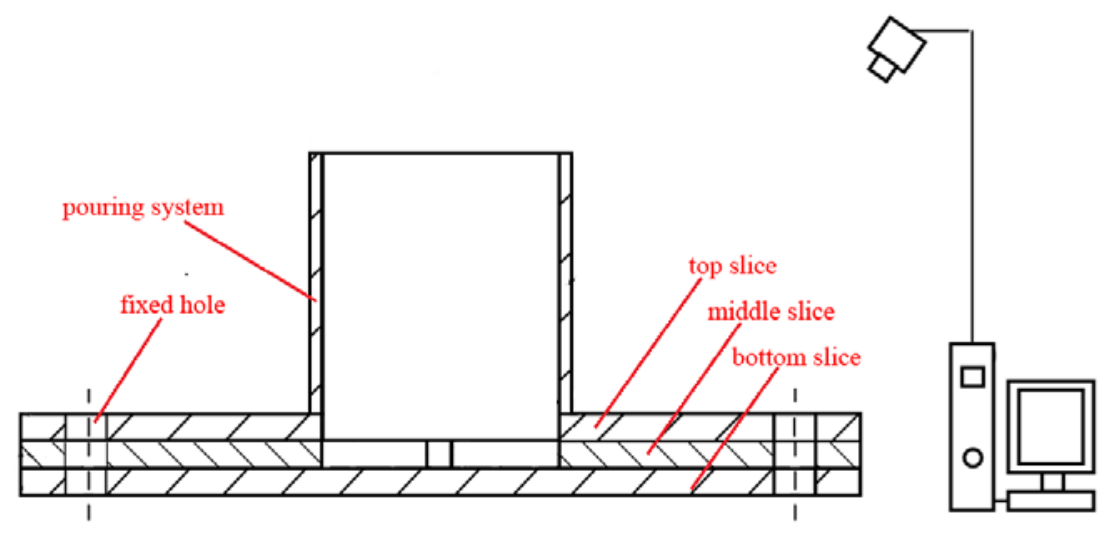

Figure 2. A-A sectional profile in Fig. 1 a)

Before the experiment has been carried out, a small piece of $\mathrm{CaC}_{2}$ particle is put into the dried bubble chamber and the chamber is tightly sealed. After that, the PMMA casting mold will be fixed on the centrifugal turntable by the four big fixed holes on the mould. When the centrifugal turntable is rotating at a certain stable rotating speed, the simulated medium will be poured into the rotating casting mold. At the meantime, the high speed camera which is preset obliquely upper the casting mould (shown in Fig. 2) will be started and the bubble moving process will be shot until the moving trajectory is steady.

The bubbles were generated by the reaction between the small $\mathrm{CaC}_{2}$ particle and the water in the simulated liquid. The bubble migration process in the simulated liquid was taken by high speed digital camera, and the photographing frequency set as 1000 frames per second. Four different casting mould rotational speeds (160, 300, 400 and 500 rpm) were used in the experiment, and the casting mould rotates clockwise in the experiment.

Additionally, the computational fluid dynamics software FLUENT 6.3 is introduced to calculate the velocity of the bubble in the melt during vertical centrifugal casting process. The twophase fluid model and the Multiple Reference Frames (MRF) method are proposed in the computation. When calculating, the casting mould walls follow no slip boundary condition.

\section{The bubble migration process}

Figures 3a) and 3b) show the hydraulic experiment result of the bubble migration in the simple mould cavity and the complex cavity when the casting mould rotates at $300 \mathrm{rpm}$. Figure 3a) shows that the bubble in the simple cavity move to the rotating shaft after it is released from the bubble generation chamber under the synthetic influence of buoyancy force (formed by the pressure difference during vertical centrifugal casting process), the centrifugal force and the coriolis force. After a period of time, the bubble migration contrail deviates from the line between the bubble initial position and the rotation shaft of the casting mould. Furthermore, the deviate direction is opposite to the rotation direction of the casting mould. That is the bubbles continue to migrate like a line parallel to the casting mould wall in the direction opposite to the rotating casting mould.

On the other aspect, the bubble migration in the simple cavity can be divided into the radial movement forward to the casting rotating shaft and the circular movement opposite to the direction of the rotating mould. And the casting mold wall has a blocking effect on the circular movement of the bubble. Therefore, the ultimate migration trajectory of the bubble at position 1 in the simple cavity is like a line close to the casting mould wall.

The bubble migration process in the complex cavity show that it is much complicated compared with the bubble migration process in the simple cavity. The bubble migration in the complex cavity can also be divided into the radial movement forward to the casting rotating shaft and the circular movement opposite to the direction of the rotating mould. The gas bubbles in the complex cavity first migrate along the casting mould wall in the opposite direction of the rotating casting mould. Then the bubbles gather at the white ellipse circle shown in Fig. 3b) because of the blocking effect of the casting mould on the radial movement of the bubble migration. After the gases reach a certain amount, they re-nucleate and form new bigger bubbles along the casting mould wall. The reformed bubbles continue to move toward the rotating shaft of the casting mould. 


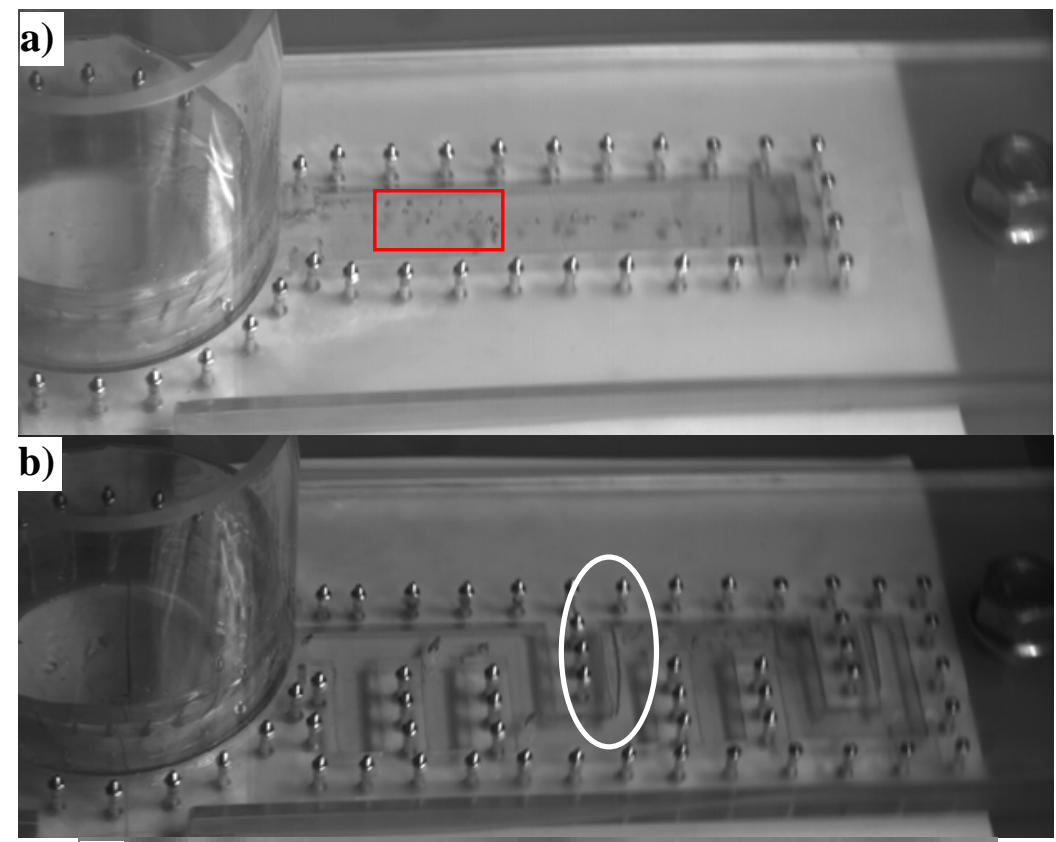

c)
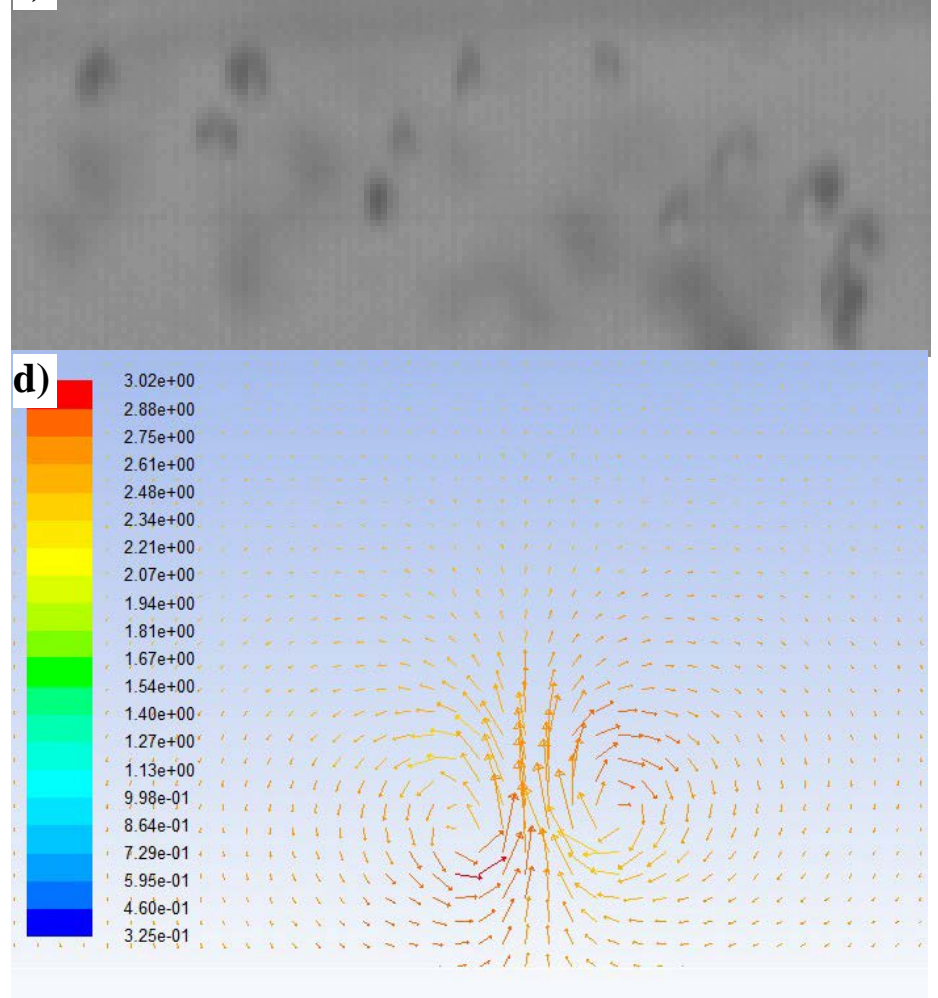

relative-velocity Colored By Velocity Magnitude (mixture) $(\mathrm{m} / \mathrm{s})($ Time $=8.0000 \mathrm{e}-03)$

Figure 3. Hydraulic experiment result of bubble migration contrail a) in the simple cavity; $b$ ) in the complex cavity; c) detailed view of rectangle in Fig3a); d) velocity vector of the bubble

In addition, the bubble morphology during its migration process under vertical centrifugal field is not a perfect sphere, but an elliptical shape (shown in Fig. 3c)). The bubble morphology can be explained by the pressure difference of bubble surface under vertical centrifugal field. The pressure of the surface that is further from the rotating shaft is bigger than that of the surface near the rotating shaft for the synthetic effect of the forces. Therefore, a jet flow is induced by the 
pressure difference and the vortex sheet coming from the bubble surface (shown in Fig. 3d)). The jet flow makes the bubble surface near the rotation shaft migrate slower than the rest parts of gas bubble. Therefore, the bubble surface further from the rotating shaft sinks and its geometry shape converts from the original round circle to an elliptical shape.

\section{The dimensional size of the bubble}

\subsection{Critical size of the bubble released from the generation chamber}

During the hydraulic model experiment, the $\mathrm{CaC}_{2}$ particles in the bubble generation chamber react vigorously with water in the simulated liquid when the liquid is poured into the casting mould and flow into the bubble generation chamber which is preset on the casting mould. Then a large number of $\mathrm{CO}_{2}$ gases generate, gather and nucleate in the generation chamber. The nucleation keeps growing up as gases in the generation chamber continue to diffuse into the nucleation core. When the bubble nucleation grows up to a certain critical size, the bubble will escape from the bubble generation chamber and enter into the simulated liquid in the casting mould. New bubble nucleation will form, grow up and escape from the bubble generation chamber until the $\mathrm{CaC}_{2}$ particles in bubble generation chamber reaction finished.

The gas bubbles that escaped from the bubble generation chamber will continue to migrate in the simulated liquid with trajectory shown in Fig. 3 which has been stated in section 3 . The critical size of bubble escaping from the bubble generation chamber will be discussed. As has been stated, the bubble morphology during vertical centrifugal field is in an elliptical shape, the bubble size will be quantified by the image analysis. The size is the average of the testing values of repeated measurements. Thus, the bubble can be considered as a ball-like sphere.

The critical size of the bubble escaping from the bubble generation chamber under different casting mould rotational speed is shown in Fig. 4. The results show that the critical size of the bubble escaping from the bubble generation chamber under $160 \mathrm{rpm}$ is $2.26 \mathrm{~mm}$. The critical size of the bubble under $300 \mathrm{rpm}$ is sharply reduced to about $1.4 \mathrm{~mm}$. The critical size of the bubble under $400 \mathrm{rpm}$ and $500 \mathrm{rpm}$ is $1.19 \mathrm{~mm}$ and $0.92 \mathrm{~mm}$, respectively. The critical size of the gas bubble escaping from the bubble generation chamber decreases with the increment of the casting mould rotational speed. This can be attributed to the pressure difference under different mould rotational speed.

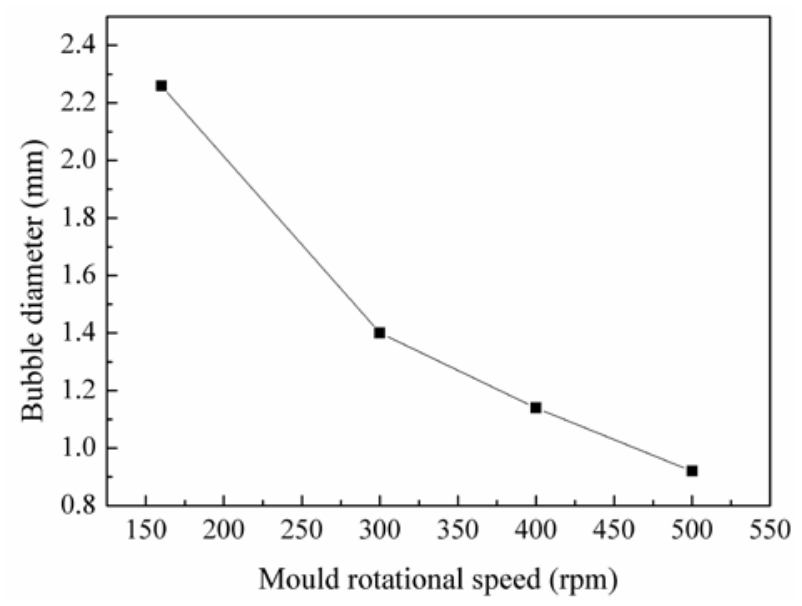

Figure 4. Bubble diameters under different mould rotational speed

The gas bubble generated in the chamber is considered as the ideal gas and the bubble is balllike when escaped. Here, the gas in the bubble can be expressed by the Clapeyron equation. Thus, the diameter of the ball-like gas bubble escaping from the bubble generation chamber can be expressed by the following equation [19],

$$
d=\sqrt[3]{6 n \mathrm{RT} / \pi P}
$$

where $P$ is the pressure of gas bubble $(\mathrm{Pa}), n$ is the molecular weight of gas in a bubble (mol), $T$ is the temperature of gas bubble $(\mathrm{K}), \mathrm{R}$ is the molar gas constant, $8.314 \mathrm{~J} /(\mathrm{mol} \cdot \mathrm{K})$.

Therefore, the diameter of the gas bubble is inversely proportional to the pressure of the gas bubble $\sqrt[3]{P}$. The centrifugal pressure of the gas bubble in the titanium alloy melt in vertical centrifugal field $P$ is [20],

$$
P=\frac{1}{2} \rho \omega^{2}\left(r^{2}-r_{0}^{2}\right)
$$

where $\rho$ is the density of the titanium alloy melt $\left(\mathrm{kg} / \mathrm{m}^{2}\right), r_{0}$ is the distance from the free surface of the titanium alloy melt to the rotating shaft, $r$ is the distance from the position of the gas bubble to the rotating shaft. 
According to equation (2), the centrifugal pressure of gas bubble in the titanium alloy melt will increase with the increment of the casting mould rotational speed. Therefore, we can know that the diameter of the gas bubble will decrease with the increment of the casting mould rotational speed when the gas bubbles release from the chamber.

\subsection{Dimensional size diversification of the bubble during the migration process}

Figure 5 is the dimensional size diversification of the bubble during its migration process to the rotating shaft when the casting mould rotates at 150 rpm. Results show that the dimensional size of the bubble increases with its migration process to the rotating shaft in the vertical centrifugal field. During the bubble migration process to the rotating shaft in the simple geometry cavity, the distance from the position of the bubble to the rotating shaft will decrease with its migration to the rotating shaft. Thus, according to the equation (2), the centrifugal pressure of the gas bubble will become smaller and smaller during its migration to the rotating shaft. Therefore, according to equation (1), the gas bubbles become much bigger during its migration to the rotating shaft than when it just released from the bubble generation chamber.

The bubble migration process in the complex geometry cavity shows that the gas bubbles will gather for the blocking effect of the casting wall on the radial movement. Then they will re-nucleate and form new bigger bubbles along the casting mould wall. On the other aspect, the number of the re-formed bubbles becomes less and the volume of the re-formed bubbles becomes much bigger than that escape from bubble generation chamber.

Figures 6a) and 6b) show the bubble migration process in the complex mould cavity when the casting mould rotates clockwise at $300 \mathrm{rpm}$ and $400 \mathrm{rpm}$. From Fig. 6 we can see that when the mould rotational speed increased from $300 \mathrm{rpm}$ to $400 \mathrm{rpm}$, the number of the re-formed bubbles becomes less and the volume of the re-formed gas bubbles becomes smaller. Thus, we can know that the number of the re-formed bubbles decreases with the increment of mould rotational speed. The dimensional size of the re-formed bubbles decreases with the increment of mould rotational speed, too.

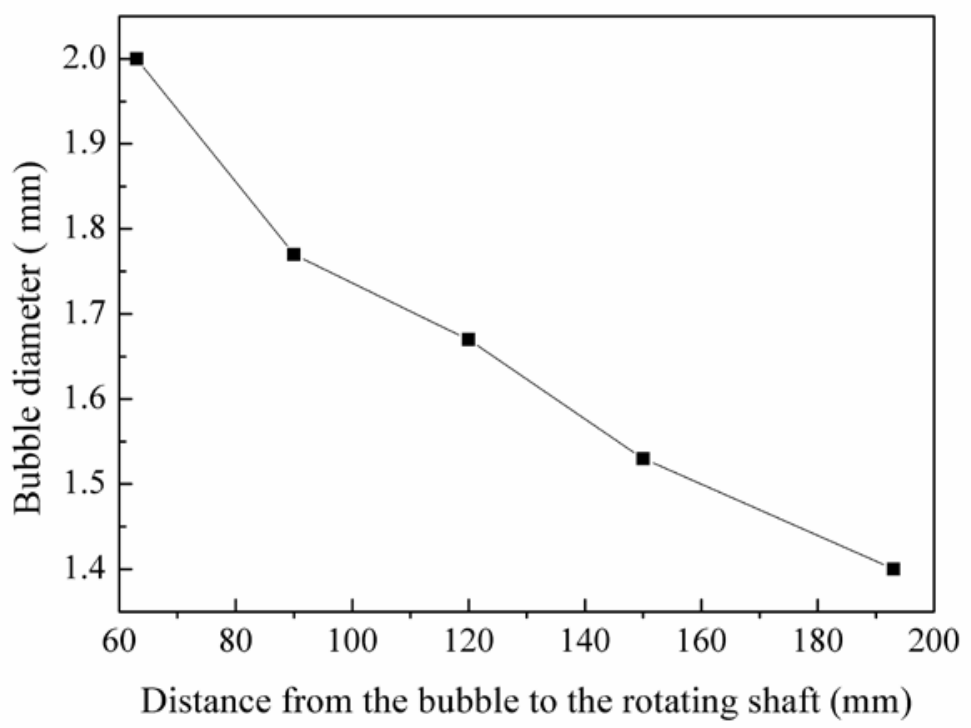

Figure 5. Dimensional size diversification of the bubble at 300 rpm in the simple cavity (clockwise) 


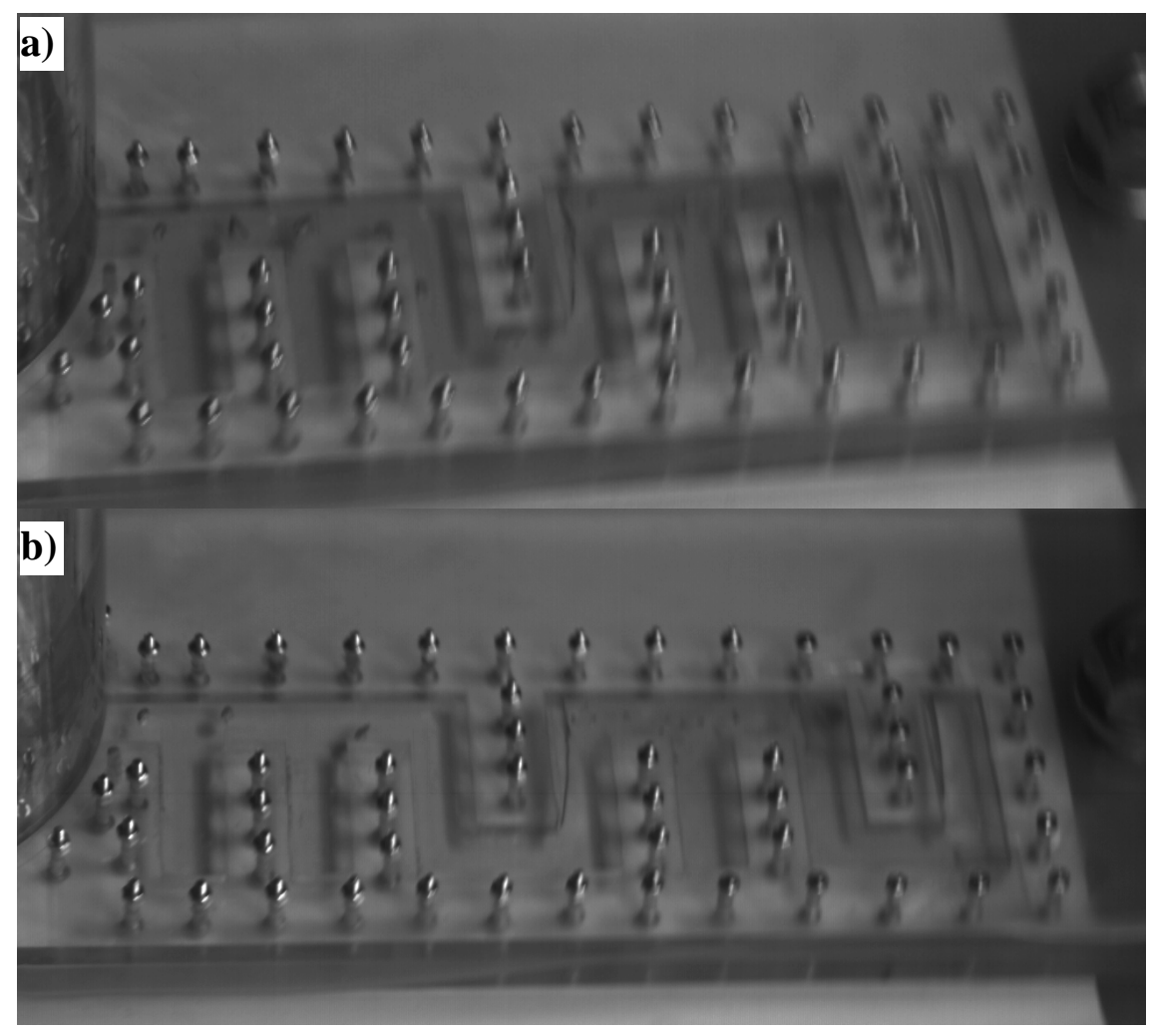

Figure 6. Migration trajectory of the bubble in complex cavity (clockwise) a) $300 \mathrm{rpm}$; b) $400 \mathrm{rpm}$

\section{Conclusion}

(1) The bubble migration process can be divided into the radial movement forward to the casting rotating shaft and the circular movement opposite to the direction of the rotating mould. The casting mould wall has a blocking effect on the movement in different mould cavities.

(2) The critical size of gas bubbles escaping from the bubble generation chamber decreases with the increment of the casting mould rotational speed. The size of the gas bubbles decreases with the increment of the casting mould rotational speed when the gas bubbles release from the chamber. The bubbles become smaller during its migration to the rotating shaft.

(3) The morphology of the gas bubble in both the simple and complex cavity during its migration process is not a perfect sphere, but an elliptical shape.

\section{Acknowledgement}

The present work is funded by the National Natural Science Foundation of China (Grant No. U1604254) and the Fundamental Research Funds for the Henan
Provincial Colleges and Universities in Henan University of Technology (Grant No. 2018QNJH25).

\section{References}

[1] Yang, Y., Chen, R., Wang, Q., Guo, J., Su, Y., Ding, H., Fu, H.: Dominant dimensionless parameters controlling solute transfer during electromagnetic cold crucible melting and directional solidifying TiAl alloys, International Communications in Heat \& Mass Transfer, 90 (2018), 56-66.

[2] Zeng, S. W., Zhao, A. M., Luo, L., Jiang, H., Zhang, L.: Development of $\beta$-solidifying $\gamma$-TiAl alloys sheet, Materials Letters, 198 (2017), 3133.

[3] Wu, S.P., Xu, Q., Zhang, J., Nan, H., Xue, X., Guo, J.: Solidified structure of thin-walled titanium parts by vertical centrifugal casting, China Foundry, 18 (2011), 2, 218-222.

[4] Tavernier, V., Millet, S., Henry, D., et al.: Overview about advanced fighter aircraft structure made with titanium, International Journal of Heat \& Mass Transfer, 110 (2017), 209-218.

[5] Williams, J. C., Starke, E. A. Jr.: Progress in 
structural materials for aerospace systems, Acta Materialia, 51(2003), 19, 5775-5799.

[6] Chan, D., Guillory, V., Blackman, R., Chung, K. H.: The effects of sprue design on the roughness and porosity of titanium castings, Journal of Prosthetic Dentistry, 78 (1997), 4, 400-404.

[7] Yang, L., Chai, L. H., Liang, Y. F., Zhang, Y. W., Bao, C. L., Liu, S. B., Lin, J.: Numerical simulation and experimental verification of gravity and centrifugal investment casting low pressure turbine blades for high $\mathrm{Nb}$-TiAl alloy, Intermetallics, 66 (2015), 149-155.

[8] Xu, Q., Wu, S. P., Xue, X.: Mold filling behavior of titanium melt in thin-walled and complicated cavities in hypergravity field, Engineering Review, 33(2013), 1, 57-63.

[9] Ermachenko, A. G., Lutfullin, R. Y., Mulyukov, R. R.: Advanced Technologies of Processing Titanium Alloys and Their Applications, Reviews on Advanced Materials Science, 29 (2011), 1:68-82.

[10] Wang, S. R., Guo, P. Q., Yang, L. Y.: Centrifugal precision cast TiAl turbocharger wheel using ceramic mold, Journal of Materials Processing Technology, 204 (2008), 1-3, 492497.

[11] Nan, H., Liu, C. K., Huang, D., Zhao, J., Zhao, H.: Precision Casting of Ti-15V-3Cr-3Al-3Sn alloy setting, China Foundry, 5 (2008), 1, 1215.

[12] Fu, P. X., Kang, X. H., Ma, Y. C., Liu, K., Li, D. Z., Li, Y. Y.: Centrifugal casting of TiAl exhaust valves, Intermetallics, 16 (2008), 2:130-138.
[13] Wu, M. H., Wagner, I., Sahm, P. R., Augthun, M.: Numerical simulation of the casting process of titanium removable partial denture frameworks, Journal of Materials Science: Materials in Medicine, 13(2002), 3:301-306.

[14] Zu, F. Q.: Principle of casting forming, China Machine Press, Beijing, 2013.

[15] Xu, Q., Wang, X., Wu, S. P.: Numerical Simulation of Bubble Migration in Liquid Titanium Melts During Vertical Centrifugal Casting Process, Journal of Harbin Institute of Technology (New Series), 28 (2018), 66-71.

[16] Sui, Y. W., Li, B. S., Liu, A. H., Xiong, Y., Guo, J., Fu, H.: Gas Bubble Growth in Vertical Centrifugal Casting Liquid Metal, Special Casting \& Nonferrous Alloys, 29 (2009),3, 580-584.

[17] Sui, Y. W., Li, B. S., Liu, A. H., Guo, J. J., Fu, H.: Infiltration flux and similarity criterion during centrifugal casting titanium alloy melts feeding, Rare Metal Materials and Engineering, 38(2009), 4,594- 598.

[18] Li, C. Y., Wu, S. P., Guo, J. J., Su, Y., Bi, W., Fu, H.: Model experiment of mold filling process in vertical centrifugal casting, Journal of Materials Processing Technology, 176 (2006), 1-3:268272.

[19] Xu, Q.: Mould filling and solidification of complicated titanium alloy casting during vertical centrifugal casting process, Harbin Institute of Technology, 2013, 119-120.

[20] Ye, X. C.: Analysis on thermodynamics and dynamics of the microstructure solidified under centrifugal pressure, Harbin Institute of Technology, 2006. 